\title{
ИЗМЕНЕНИЕ УРОВНЯ РН СЛЮНЫ ПРИ ПРОТЕЗИРОВАНИИ БЕЗЗУБЫХ ЧЕЛЮСТЕЙ РАЗЛИЧНЫМИ БАЗИСНЫМИ ПЛАСТМАССАМИ
}

\section{CHANGES IN THE PH LEVEL OF SALIVA WHEN PROSTHETICS OF EDTLESS JAWS WITH VARIOUS BASE PLASTICS}

A. Ertesyan

Summary. In this study, we studied the change in the $\mathrm{pH}$ level in unstimulated saliva of the sublingual gland before and after the application of complete removable plate prostheses made of photopolymer resins for 3D printing and acrylic plastics. The best result was observed in patients with complete removable dentures made of: Denture $3 \mathrm{D}+-6.59 \pm 1.24$ and $6.65 \pm 1.24,7$ and 21 days, respectively; Denture Base, 7 days $-6.71 \pm 0.98,21$ days $-6.64 \pm 1.28$. Having conducted a study to study the $\mathrm{pH}$ values in the unstimulated saliva of the hyoid gland, it can be concluded that the $\mathrm{pH}$ of saliva in patients with complete removable dentures made of photopolymer resins for SLA printing on a Denture 3D+3D printer, Denture Base on days 7 and 21 is statistically and reliably less than Ftorax and Rapid Simplified hot curing plastics.

Keywords: complete removable plate prosthesis, complete absence of teeth, acrylic plastic, photopolymer resin, additive technologies, 3D printing, saliva.

\author{
Эртесян Альберт Робертович \\ К.м.н., ассистент, ФГБОУ ВО «Самарский \\ государственный медицинский университет» \\ Минздрава России, Самара \\ albertertesyan@gmail.co
}

Аннотация. В данном исследовании проводилось изучение изменение уровня рН в нестимулированной слюне подъязычной железы до и после наложения полных съемных пластиночных протезов из фотополимерных смол для 3D печати и акриловых пластмасс. Наилучший результат наблюдали у пациентов с полными съемными протезами, изготовленными

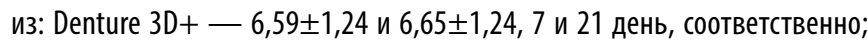

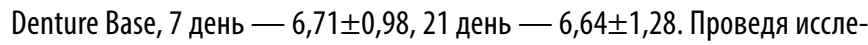
дование на изучение значений рН в не стимулированной слюне подъязычной железы, можно сделать заключение 0 том, что рН слюны у пациентов с полными съемными протезами из фотополимерных смол для SLA печати на 3D принтере Denture 3D+, Denture Base на 7 и 21 день статистически и достоверно меньше чем из пластмасс горячего отверждения Фторакс и Rapid Simplified.

Ключевые слова: полный съемный пластиночный протез, полное отсутствие зубов, акриловая пластмасса, фотополимерная смола, аддитивные технологии, 3D печать, слюна.

\section{Введение}

$\Pi$ олные съемные протезы являются наиболее распространенным методом лечения пациентов с полным отсутствием зубов [1]. Возможны некоторые временные проблемы, которые могут возникнуть после наложения полных съемных протезов, которые могут длиться в течение нескольких недель, вызывая различные уровни боли, дискомфорта и функциональных трудностей.

Факторы, влияющие на адаптацию пациента к зубным протезам, до конца не изучены. Предыдущие исследования изучали такие факторы, как качество зубных протезов, состояние слизистой полости рта, взаимоотношения пациента и стоматолога - ортопеда, личность пациента, социально-экономические факторы и многое другое. Однако некоторые из этих факторов лишь слабо коррелируют с удовлетворенностью пациента съемными протезами, которая определяется индивидуально и часто непредсказуема как для пациента, так и для стоматолога - ортопеда [2].

Использование полных съемных протезов могут быть предрасполагающим фактором для возникновения изменений в слюне, которые влияют на гомеостаз полости рта и здоровье слизистой оболочки полости рта и оказывают пагубное влияние на качество жизни, связанное со здоровьем полости рта, особенно у пожилых людей, которые являются наиболее распространенной группой пациентов с адентией [3]. В первые дни после наложения полных съемных протезов обычно наблюдаются поврежденная слизистая оболочка. Некоторые исследования сообщают об изменениях состава слюны в этот период, в частности уровня $\mathrm{pH}$ [4]. Однако до сих пор неясно, влияют ли эти изменения на адаптацию пациента к съемному протезу и какие компоненты слюнных желез играют соответствующую роль в этом процессе. 


\section{Шель исслеАования}

Изучение изменение уровня $\mathrm{pH}$ в нестимулированной слюне подъязычной железы после наложения полных съемных пластиночных протезов из фотополимерных смол и акриловых пластмасс.

\section{Материалы и методы исследования}

Исследуемая выборка включала последовательную группу пациентов с полным отсутствием зубов на верхней и нижней челюстях, которые ранее не использовали полные съемные протезы. Участники должны продемонстрировать хорошее общее состояние здоровья и отсутствие местных или медицинских противопоказаний для лечения. Кроме того, предполагалось, что люди будут психически и физически здоровы.

Перед проведением исследования, проводили подробный инструктаж пациента - объясняли методику проведения процедуры сбора слюны. Слюну собирали натощак (после ночного перерыва в приеме пищи) или через 2-2,5 часа после приема пищи. Пациента заблаговременно предупреждали и просили не делать того, что может стимулировать слюноотделение, до самой процедуры сбора. Запрет включал, жевание пищи, жевательной резинки, конфет, курение, полоскание полости рта, питье и т.д. Тест проводили в спокойной обстановке.

Пациента усаживали, просили опустить голову и сидеть в таком положении, не глотать слюну и не двигать губами и языком во время всего периода сбора слюны.

Не стимулированные образцы цельной слюны отбирали до наложения съемного протеза, через 7 дней, 21 день, 30 дней и 6 месяцев после использования съемных протезов. Для проведения сбора слюны перед наложением протеза в подъязычную область (в области переднего края уздечки языка) помещали стерилизованный цилиндрический кусочек ваты на 4 мин, затем его удаляли и сжимали одноразовым шприцем в стерильную пробирку объемом 2,0 мл. Когда необходимый объем в 1,5 мл не был достигнут, процедуру повторяли.

Оценка рН слюны проводилась с использованием индикаторов McolorpHastTM pH 4,0-7,0 (Merck, Германия). Полоска индикатора опускалась в пробирку с только что собранным образцом слюны на 10 секунд и цвет тестполоски сравнивался со шкалой на упаковкe.

Полные съемные протезы были изготовлены из акриловых базисных пластмасс горячего отверждения Фторакс компании «Стома» (Украина), Rapid
Simplified компании «Vertex-Dental B.V.» (Нидерланды), и фотополимерных смол для печати на 3D принтере Denture 3D+ компании «NextDent B.V.» (Нидерланды) и Denture Base компании «Formlabs» (США).

В данном исследовании приняли участие 20 пациентов с полным отсутствием зубов: 14 женщин и 6 мужчин, средний возраст которых составил $64,4 \pm 8,3$ года.

Данные были представлены в терминах медианы, диапазона и среднего значения (и стандартной ошибки, SE). Анализ данных включал изменения показателей слюны до и после наложения съемных протезов. Для групповых сравнений на уровне значимости 0,05 использовались непараметрический критерий Крускала-Уоллиса. Для анализа данных использовались IBMSPSS20.0 (Чикаго, Иллинойс, США) и GraphPad Prism 5.0 (Сан-Диего, Калифорния, США).

\section{Результаты исслеАования и их обсужАения}

За норму показателей рН в слюне, взяты значения $\mathrm{pH}$ до наложения полных съемных пластиночных протезов.

Средние уровни значений $\mathrm{pH}$ в слюне до наложения полных съемных пластиночных протезов, через 30 дней и 6 месяцев находились в пределах нормы, различия не были статистически не значимыми, и составили: до наложения, Фторакс - 6,75 $\pm 0,98,6,77 \pm 1,07-30$ дней

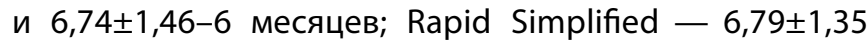

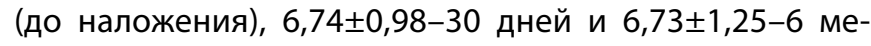

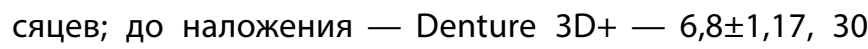

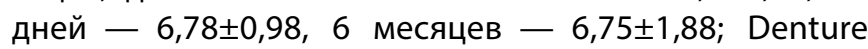
Base $-6,65 \pm 1,71$ (до наложения), 30 дней $-6,71 \pm 1,23$, через 6 месяцев -6,73 $\pm 1,13$.

Статистически более значимыми значениями pH слюны были на 7 и 21 день пользования полными съемными пластиночными протезами, изготовленными из Фторакс и Rapid Simplified. Значения $\mathrm{pH}$

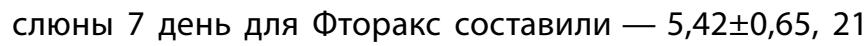

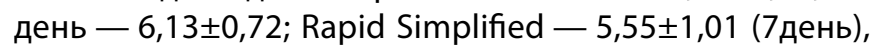
6,35 $\pm 1,47-21$ день.

Наилучший результат наблюдали у пациентов с полными съемными протезами, изготовленными из:

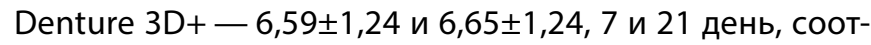

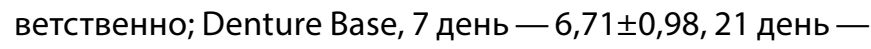
$6,64 \pm 1,28$.

Предыдущие исследования приводили к противоречивым выводам относительно изменений состава слюны после установки новых зубных протезов. Bhat S.V., et 
al. [4] обнаружили снижение уровня рН слюнных желез, тогда как Nikolopoulou F., et al. [5] наблюдались более высокие значения $\mathrm{pH}$ через 15 дней после наложения полных съемных протезов. В нашем исследовании наблюдались достоверные различия $\mathrm{pH}$ на протяжении всего оцениваемого периода у пациентов с протезами, изготовленными из Фторакс и Rapid Simplified. Важно отметить, что у пациентов, из базисной пластмассы Denture 3D+ и Denture Base не наблюдалось статистически значимых изменений.

Исследования, включающие анализ значений $\mathrm{pH}$ у пациентов с полным отсутствием зубов, очень редки. Исследование Rocha M.S. et al. [6] показало, что значе- ния $\mathrm{pH}$ в слюне значительно выше у пациентов с частичным отсутствием зубов, поскольку зубы могут влиять на значения $\mathrm{pH}$.

\section{Выво $\triangle \mathrm{b}$}

Таким образом, проведя исследование на изучение значений $\mathrm{pH}$ в не стимулированной слюне подъязычной железы, можно сделать заключение о том, что рН слюны у пациентов с полными съемными протезами из фотополимерных смол для SLA печати на 3D принтере Denture 3D+, Denture Base на 7 и 21 день статистически и достоверно меньше чем из пластмасс горячего отверждения Фторакс и Rapid Simplified.

\section{ЛИТЕРАТУРА}

1. Мячина О.В., Зуйкова А.А., Пашков А.Н. Особенности секреции оксида азота в слюнных железах человека в норме и при патологии / 0.В. Мячина, А.А. Зуйкова, А.Н. Пашков // Вестник ВГУ. Серия: Химия. Биология. Фармация. - 2006. — № 1.—C. 137-140.

2. Еловикова Т.М. Слюна как биологическая жидкость и ее роль в здоровье полости рта: Учебное пособие / Еловикова Т.М., Григорьев С.С.- Екатеринбург: Издательский Дом «ТИРАЖ».— 2018.— 136 с.

3. Bekiroglu N., Çiftçi A., Bayraktar K. Oral complaints of denture-wearing elderly people living in two nursing homes in Istanbul, Turkey / N. Bekiroglu, A. Çiftçi, K. Bayraktar // Oral Health and Dental Management. — 2012.—V. 11.— № 3.—P. 107-115.

4. Bhat S.V., Rao N.L., Naushad P. Salivary uric acid, C- reactive protein and pH levels in completely edentulous patients before and after wearing complete dentures / S.V. Bhat, N.L. Rao, P. Naushad // International Journal of Pharmaceutical Sciences Review and Research.— 2014.— V. 28. — № 1.—P. 38-42.

5. Nikolopoulou F., Tzortzopoulou E. Salivary pH in edentulous patients before and after wearing conventional dentures and implant overdentures: a clinical study / F. Nikolopoulou, E. Tzortzopoulou // Implant Dentistry. — 2017. — V. 16. — № 4. — P. 397-403.

6. Rocha M.S., Jesus N.R., Rocha F.S. Saliva versus peri-implant inflamation. Quantification of N0 and MCP-1 in partial and total toothless patients / M.S. Rocha, N.R. Jesus, F.S. Rocha // Revista Odontológica do Brasil Central. — 2018. — V. 21. — № 56. — P. 389-393. 